\title{
Friction and Structural Responses of Ion Implanted Polyoxymethylene Copolymer (POM-C)
}

\author{
Md. Shahinur Rahman ${ }^{1 *}$, Konstantin Lyakhov ${ }^{1}$, Jong-Keun Yang ${ }^{1}$, \\ Muhammad Athar Uddin ${ }^{2}$ and Muhammad Sifatul Alam Chowdhury ${ }^{2}$ \\ ${ }^{1}$ Department of Nuclear and Energy Engineering, Jeju National University, \\ Jeju 63243, Republic of Korea. \\ ${ }^{2}$ Department of Electrial and Electronic Engineering, International Islamic \\ University Chittagong, Chittagong, Bangladesh. \\ *Corresponding author: shahineee33@gmail.com
}

\begin{abstract}
Polyoxymethylene copolymer (POM-C) round block was implanted with $120 \mathrm{KeV}$ ions of $\mathrm{He}$ to doses of $5 \times 10^{16}$ and $1 \times 10^{16}$ ions $\mathrm{cm}^{-2}$. It was also implanted with $120 \mathrm{KeV}$ ions of $\mathrm{Ar}+\mathrm{He}$ and $\mathrm{He}+\mathrm{Ne}$ to dose of $1 \times 10^{16}$ ions $\mathrm{cm}^{-2}$, respectively. The friction coefficient behavior of both implanted and unimplanted POM-C blocks was investigated using a ball on disk tribometer mechanism. The friction coefficient of He ion implanted POM-C block at a dose of $5 \times 10^{16}$ ions $\mathrm{cm}^{-2}$ is lowest compared to all unimplanted and others ions doses implanted POM-C blocks. It also shows the moderate surface texturing (atomic rearrangement), lower surface micro-hardness and average surface roughness compared to both unimplanted and other ions doses implanted POM-C blocks due to well adjusted carbonization, cross-linking and ions-target atoms collisions, which is ascertained from SEM-EDS, Raman spectroscopic and surface profiling observations. The other ions doses implanted POM-C blocks demonstrate the higher friction coefficient and surface roughness with polymer surface deformation (crazing, cracking, pitting and gas evolution, bond breaking) due to severe chain scission, surface dose delivered atomic displacements and chemical structural degradation. It is concluded that the variation in friction coefficient behavior of POM-C block resulted from its structural response for ion beam implantation on the top surface.
\end{abstract}

Keywords: POM-C; SEM; Ion - implantation; Friction- coefficient; Raman- spectroscopy.

\section{INTRODUCTION}

Polymers have been widely used in many sophisticated fields due to low density, mold ability, low manufacturing cost, and good mechanical and electrical / electronic properties. Polyoxymethylene copolymer (POM-C) is an attractive copolymer to make small gear wheels, bearings, seals, precision parts, automotive and consumer electronics [1 - 2]. However, its use in extreme operating condition is sometimes limited due to its undesired properties of the surface (friction, wear and chemical resistivity) [3 - 5]. Therefore, it's very crucial issue to modify the surface mechanical and morphological properties in a controlled manner to expand POM-C applications in low and high tech areas with good processibilities. Ion implantation is an established powerful method for modification the physical and chemical properties of polymers up to several micrometers thickness [1 - 8]. This established method operates at low temperature in vacuum condition without any thermal degradation of pure material. It's a very effective technique in surface modification due to its higher cross section for prompt ionization and larger 
linear energy transfer capability [7 - 10]. Ion implantation can easily improve the surface mechanical properties (friction, hardness, surface roughness and wettability) through precise cross-linking. Cross-linking can easily initiate strong chemically bonded networks, rigidity of backbone frame, anchoring joints for the molecular chain and restraining of atomic displacement [7 - 14]. Moreover, the judicious choice of ion implantation condition can give precise modification of surface properties depending upon chemical and physical factors of target polymeric material [10 - 14].

The key objective of this study is to reduce the friction phenomena up to desired level through ion beam induced physical and chemical properties modifications at molecular scale.

\section{EXPERIMENTAL}

The POM-C (Natural) blocks used were supplied from DYNEX engineering plastic company (South Korea). The dimension of the used POM-C block sample was d $30 \mathrm{~mm} \mathrm{x}$ $10 \mathrm{~mm}$. The samples were polished to the roughness $\mathrm{R}_{\mathrm{a}}=0.381 \mu \mathrm{m}$ before ion implantation. The friction coefficient was measured on a J\&L tech tribometer using a ball (SUJ 52100) on disk method at linear speed $100 \mathrm{~mm} / \mathrm{s}$. The load was $1 \mathrm{~N}$ and the sliding distance was $102 \mathrm{~m}$ over a period of 17 minutes. The morphology and weight $\%$ of $\mathrm{C}$ of all unimplanted and ions doses implanted POM-C blocks were observed using scanning electron microscopy (SEM) coupled with EDS technique at 500x magnification. The surface micro-hardness test was performed using a triboindenter (Hysitron TI 950) at $1000 \mathrm{~nm}$ nano-indentation depth. The surface roughness was measured using 3D nano surface profiler at $20 \mathrm{x}$ objective. The chemical structural analysis was analyzed using Raman spectroscopy. The ion implantation was performed on the KE04-01 (CockcroftWalton) low energy ion implanter with the energy of $120 \mathrm{KeV}$. The ion beam current was $2 \mu \mathrm{A}$. The following ions doses conditions were selected for our study:

(a) He ions to doses of $5 \times 10^{16}$ and $1 \times 10^{16}$ ions $\mathrm{cm}^{-2}$

(b) $\mathrm{Ar}+\mathrm{He}$ and $\mathrm{He}+\mathrm{Ne}$ to doses of $1 \times 10^{16}$ ions $\mathrm{cm}^{-2}$.

\section{RESULTS AND DISCUSSION}

\section{A. Friction coefficient}

In this study, friction coefficient reduction at intricate operating condition is taken into consideration, where conventional lubricating technique is not applicable. The friction coefficient phenomena for all unimplanted and different ions doses implanted POM-C blocks is shown in Fig. 1 (a -e). The friction coefficient of 0.20 is observed for unimplanted POM-C block surface shown in Fig. 1-a. The friction coefficient of He ion implantation at a dose of $5 \times 10^{16}$ ions $\mathrm{cm}^{-2}$ is lowest $(0.15)$ among all unimplanted and others ions doses implanted POM-C blocks shown in Fig. 1-b . It might be the reason of volatile molecules formation (carbon free radicals) and structural transformations (atomic rearrangement due to collisions between ions and target atoms of exposed polymer) on the top surface of POM-C block by ion beam induced irreversible changes [6 - 14]. The threshold value of cross-linking can easily initiate free radicals formation on the top surface of target material, which can play a role as solid lubricant [10 - 14]. The solid lubricant layer formation can reduce the friction coefficient during dry sliding condition at extreme operating environment. Other ions doses implantation increased friction 
coefficient due to huge chain scission (dominant over cross-linking), surface dose delivered atomic displacement and polymeric bond breakage depending on physical and chemical factors shown in Fig. 1 (c - e) [12 - 14].

So, He ion implantation at a dose of $5 \times 10^{16}$ ions $\mathrm{cm}^{-2}$ is well suited to reduce friction coefficient depending on ion bombardment initiated chain reactions.

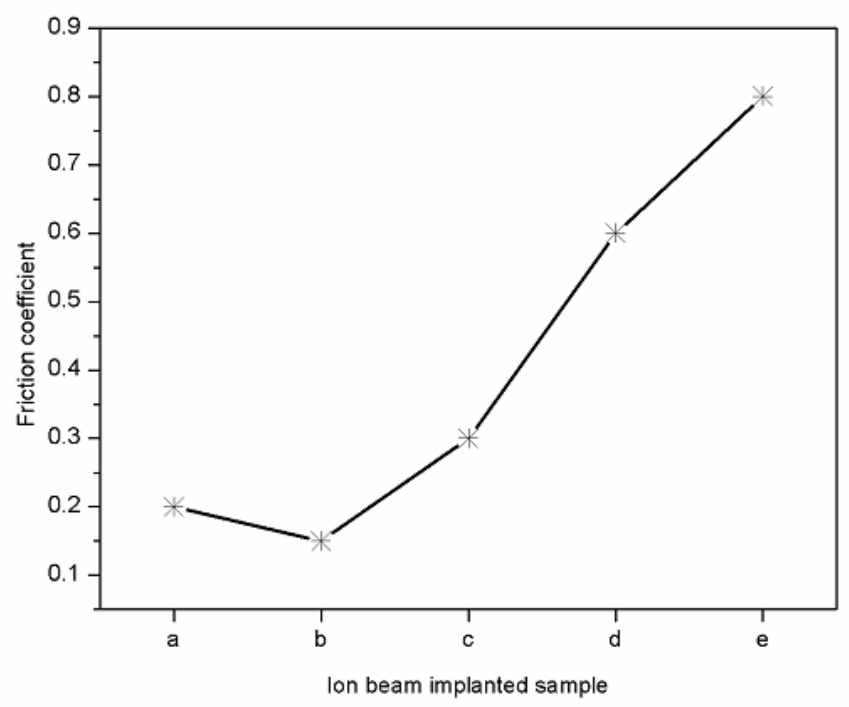

Fig. 1. Friction coefficient with different ions doses implantation: (a) unimplanted, (b) He $5 \times 10^{16}$, (c) $\mathrm{He} 1 \times 10^{16}$, (d) $\mathrm{Ar}+\mathrm{He} 1 \times 10^{16}$ and (e) $\mathrm{He}+\mathrm{Ne} 1 \times 10^{16}$ ions $\mathrm{cm}^{-2}$ implanted surfaces (load: $1 \mathrm{~N}$, sliding distance: $102 \mathrm{~m})$.

\section{B. Morphology and weight \% of $\mathrm{C}$ analysis}

Morphology and weight $\%$ of $\mathrm{C}$ analysis of different ion beam doses implanted POM-C blocks were investigated by SEM coupled with EDS facility at $5 \mathrm{KeV}$ accelerating voltage and 500x magnification. The unimplanted POM-C surface demonstrates the scuffing, ribbon tracks, waves and flaws on the surface shown in Fig. 2-a. The He ion implantation at a dose of $5 \times 10^{16}$ ions $\mathrm{cm}^{-2}$ makes the surface smooth with mild scuffing and very less ribbon tracks due to elastic nuclear collisions at the time of energy transfer from an incident ion to target polymeric atom shown in Fig. 2-b [7 - 10]. The He ion implantation at a dose of $5 \times 10^{16}$ ions $\mathrm{cm}^{-2}$ also increase the weight $\%$ of $\mathrm{C}$ significantly among all unimplanted and others ions doses implanted POM-C blocks shown in Fig. 3-b. Others ion doses implanted POM-C surfaces demonstrate the huge crazing, cracking, hillocks, deformation and atomic displacements due to energy transfer in binary nuclear collisions and huge gas evolution shown in Fig. 2 (c - e) [11 - 14]. Others ions doses also gradually reduce the weight $\%$ of $\mathrm{C}$, which might be the reason of physical and chemical structural degradation shown in Fig. 3 (c-e). 

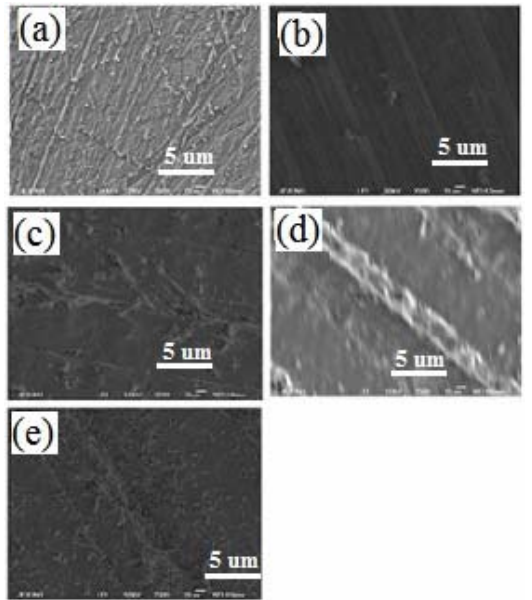

Fig. 2. SEM images on POM-C surfaces: (a) unimplanted, (b) He $5 \times 10^{16}$, (c) He 1 x $10^{16}$, (d) $\mathrm{Ar}+\mathrm{He} 1 \times 10^{16}$ and (e) $\mathrm{He}+$ Ne $1 \times 10^{16}$ ions $\mathrm{cm}^{-2}$ implanted surfaces. Scale bar $5 \mu \mathrm{m}$ in each case.

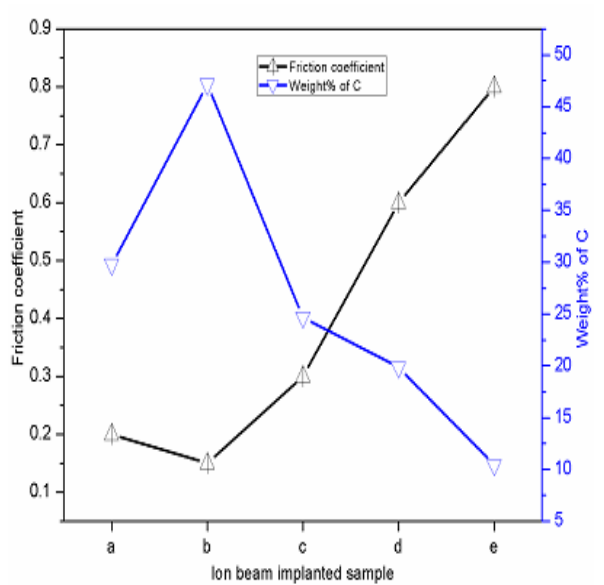

Fig. 3. Correlation between friction coefficient and weight $\%$ of $\mathrm{C}$.

\section{Surface micro-hardness:}

The surface micro-hardness test of different ion beam doses implanted POM-C blocks surfaces was performed at $1000 \mathrm{~nm}$ nano-indentation depth on five different locations. The surface micro-hardness could change by radiation induced cross-linking and chain scission in polymeric materials [4, $12-14]$. The quantitative variation in surface microhardness for all unimplanted and ion beam doses implanted POM-C blocks is shown in Fig. $4(\mathrm{a}-\mathrm{e})$. The surface micro-hardness of unimplanted POM-C block is $180 \mathrm{MPa}$ shown in Fig. 4-a, and the micro-hardness of He ion implantation at a dose of $5 \times 10^{16}$ ions $\mathrm{cm}^{-2}$ is $160 \mathrm{MPa}$ shown in Fig. 4-b. The reduced micro-surface hardness by He ion implantation at a dose of $5 \times 10^{16}$ ions $\mathrm{cm}^{-2}$ also reduce the surface dry sliding friction coefficient shown in Fig. 5-b. It may due to the formation of thin carbonization layer on the top surface of POM-C block, which may act as a solid lubricant during dry sliding friction [6 - 13]. The carbonization can form by radiation induced cross-linking and chain scission depending on predominant behavior of irradiated material [12 - 14]. The enhancement of carbonization for He ion implantation at a dose of $5 \times 10^{16}$ ions $\mathrm{cm}^{-2}$ is also observed from EDS analysis. In Fig. 4 (c - e), the micro-hardness of He 1 x $10^{16}$, Ar $+\mathrm{He} 1 \times 10^{16}$ and $\mathrm{He}+\mathrm{Ne} 1 \times 10^{16}$ ions $\mathrm{cm}^{-2}$ doses implanted surfaces increase linearly to 200,240 and $270 \mathrm{MPa}$, respectively. The increases of micro-hardness also increase the dry sliding friction coefficient linearly. 


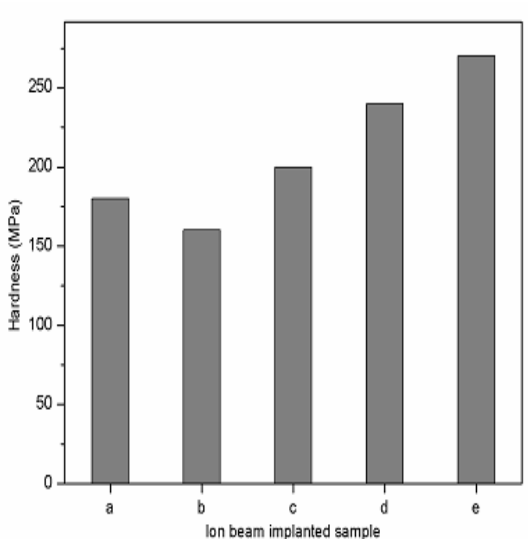

Fig. 4. Variation in Surface micro hardness.

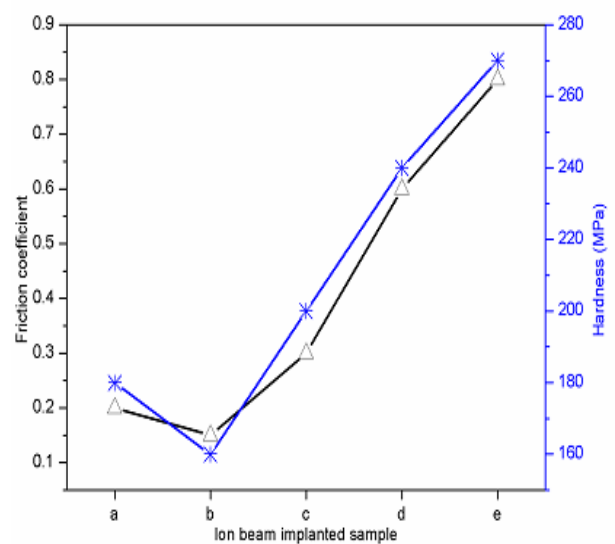

Fig. 5. Correlation between Friction coefficient and Hardness.

\section{Chemical structure:}

Raman spectroscopy is a well established non-destructive powerful technique to analyze rotational and vibrational transitions in molecular scale for solid surface, which can determine the degree of cross-linking [15]. The chemical structural modification induced by ion beam implantation on POM-C blocks was observed using Raman spectroscopy shown in Fig. 6 (a-e). The unimplanted POM-C polymer block demonstrates the following peak vibrational assignments: $994 \mathrm{~cm}^{-1}\left(\mathrm{r}, \mathrm{CH}_{2}\right), 1109 \mathrm{~cm}^{-1}\left(\mathrm{v}_{\mathrm{a}}, \mathrm{C}-\mathrm{O}-\mathrm{C}\right), 1328$ $\mathrm{cm}^{-1}\left(\mathrm{t}, \mathrm{CH}_{2}\right)$ and $1484 \mathrm{~cm}^{-1}\left(\delta, \mathrm{CH}_{2}\right)$ shown in Fig. 6-a. The He ion implantation at a dose of $5 \times 10^{16}$ ions $\mathrm{cm}^{-2}$ significantly increased the peak intensity and vibrational band strength of asymmetrical stretching at wave numbers $1109 \mathrm{~cm}^{-1}$ due to suitable crosslinking, polymerization and chemical free radicals formation in polymeric molecular bonds, which can prevent from any kinds of molecular degradation shown in Fig 6-b [15 16]. Other ions doses implantation broke the polymeric bonds with new types of bond evolution shown in Fig. 6 (c - e), which can be the reason of chain scission and ion induced inelastic collisions between ions and target atoms [11 - 16]. 


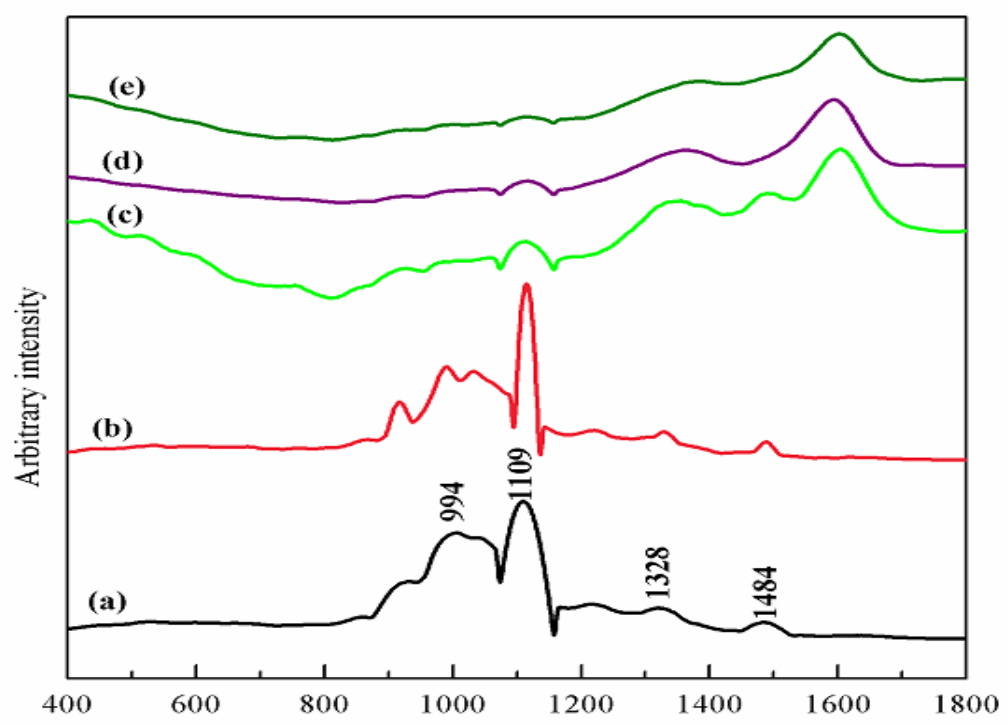

Fig. 6. Raman spectra demonstrating the effects of ion beam implantation on POM-C blocks.

\section{E. Surface roughness:}

Ion bombardment initiated surface roughness changes are demonstrated in Fig. $7(\mathrm{a}-\mathrm{e})$. The average surface roughness $\left(\mathrm{R}_{\mathrm{a}}\right)$ of unimplanted POM-C block was $381.10 \mathrm{~nm}$ shown in Fig. 7-a, and the $\mathrm{R}_{\mathrm{a}}$ of He ion implanted POM-C block at a dose of $5 \times 10^{16}$ ions $\mathrm{cm}^{-2}$ was $337.38 \mathrm{~nm}$ shown in Fig 7-b. The He ion implantation at a dose of $5 \times 10^{16}$ ions $\mathrm{cm}^{-2}$ reduced the average surface roughness significantly, which might be the reason of threshold value of cross-linking and well controlled physical sputtering effects, when atomic displacements and aggregation are suppressed [4 - 12]. The threshold value of cross-linking and controlling of atomic displacements depends on chemical and physical factors of ion bombarded polymeric material [11 - 12]. In Fig. 7 (c - e), other ion implanted doses increase the surface roughness due to huge atomic sputtering and electronic excitation effects (inelastic scattering), which deforms the polymer surface [6 $12]$.

So, He ion implantation at a dose of $5 \times 10^{16}$ ions $\mathrm{cm}^{-2}$ is best compared to other ions doses implantation to reduce surface roughness. 
(a)

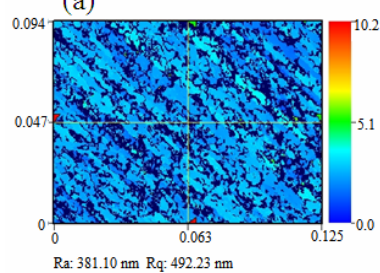

(d) (b)

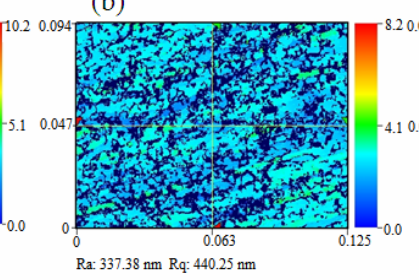

(e) (c)

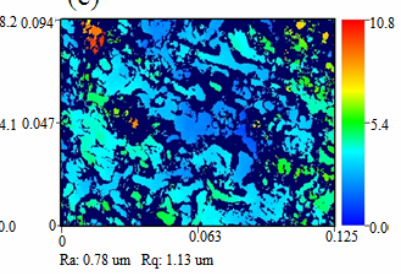

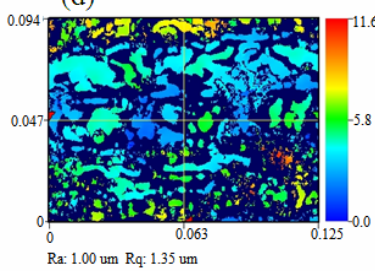

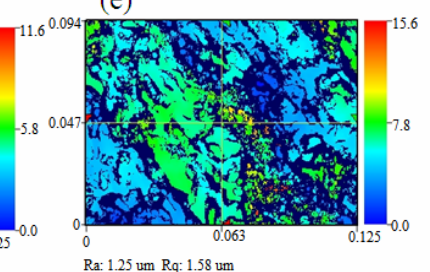

Ra: 1.25 um Rq: 1.58 um

Fig. 7. 2D surface profiling images on POM-C blocks at 20x objective: (a) unimplanted, (b) $\mathrm{He} 5 \mathrm{x}$ $10^{16}$, (c) $\mathrm{He} 1 \times 10^{16}$, (d) $\mathrm{Ar}+\mathrm{He} 1 \times 10^{16}$ and (e) $\mathrm{He}+\mathrm{Ne} 1 \times 10^{16}$ ions $\mathrm{cm}^{-2}$ doses implanted surfaces.

\section{CONCLUSIONS}

From the aforementioned study, it is concluded that the He ion implantation at a dose of 5 x $10^{16}$ ions $\mathrm{cm}^{-2}$ reduced friction coefficient by decreasing surface micro-hardness, average surface roughness and atomic displacements significantly with increasing weight $\%$ of $\mathrm{C}$, which might be the reason of carbonization, free radicals formation, radiation induced well adjusted cross-linking and partial physical degradation (smoothness by ion induced elastic nuclear collisions).

After all, friction coefficient reduction depends on ion fluence conditions, chemical and physical factors of target material.

\section{Acknowledgements}

This study was financially and technically supported by Professor Dr. Heon-Ju Lee (Nuclear Fusion and Plasma Applications Laboratory, Nuclear and Energy Engineering, Jeju National University, Jeju 63243, Republic of Korea). The authors also acknowledge the assistance of Dr. B.H Choi (KAPRA, Gangwon-do, Republic of Korea) for providing ion implantation facility.

\section{References}

[1] V.N. Popok: "Ion Implantation of Polymers: Formation of Nanoparticulate Materials," Reviews on Advanced Materials Science, vol. 30, no. 1, pp. 1-26, 2012.

[2] A. Turos, J. Jagielski, L. Slusarski and N.K. Madi: "Ion beam modification of surface properties of polyethylene," Vacuum, vol. 70, pp. 201-206, 2003.

[3] R.C. Ramola, S. Chandra, A. Negi, J.M.S. Rana, S. Annapoorni, R.G. Sonkawade, P.K. Kulriya and a. Srivastava: "Study of optical band gap, carbonaceous clusters and structuring in CR-39 and PET polymers irradiated by $100 \mathrm{MeV}$ O7+ ions," Physica B: Condensed Matter, vol. 404, no. 1, pp. 26-30, 2009. 
[4] J. Jagielski: "Friction properties of ion-beam modified materials: Where can we search for practical applications of ion implantation?," Vacuum, vol. 78, no. 2,-no. 4, pp. 409-415, 2005.

[5] L. Calcagno, G. Compagnini and G. Foti: "Structural modification of polymer films by ion irradiation," Nuclear Instruments and Methods in Physics Research Section B: Beam Interactions with Materials and Atoms, vol. 65, no. 1,-no. 4, pp. 413-422, 1992.

[6] K.A. Murray, J.E. Kennedy, B. Mcevoy, O. Vrain, D. Ryan, R. Cowman and C.L. Higginbothama: "Characterisation of the Surface and Structural Properties of Gamma Ray and Electron Beam Irradiated Low Density Polyethylene," International Journal of Material Science (IJMSCI), vol. 3, no. 1, pp. 1-8, 2013.

[7] R.L. Clough: "High-energy radiation and polymers : A review of commercial processes and emerging applications," Radtech Conference, vol. 185, pp. 8-33, 2001.

[8] Z. Tang, M. Wang, Y. Zhao and G. Wu: "Tribological properties of radiation cross-linked polytetrafluoroethylene sheets," Wear, vol. 269, no. 5,-no. 6, pp. 485-490, 2010.

[9] W. Schnabel: "Polymers and Electromagnetic Radiation," Wiley-VCH Verlag GmbH \& Co. KGaA, Weinheim, Germany, 2014.

[10] Stephen C. Lapin: "Modification of Polymer Substrates using Electron Beam Induced Graft Copolymerization," Radtech Conference, no. 2, 2014.

[11] E. Reichmanis, C.W. Frank, J.H. O’Donnell and D.J.T. Hill: "Radiation Effects on Polymeric Materials," Irradiation of Polymeric Materials. pp. 1-8, American Chemical Society (1993).

[12] J.H. O'Donnell: "Radiation Chemistry of Polymers," The Effects of Radiation on HighTechnology Polymers. pp. 1-13, ACS (1989).

[13] R. Gopal, M. Zuwei, S. Kaur and S. Ramakrishna: "Surface Modification and Application of Functionalized Polymer Nanofibers," Molecular Building Blocks for Nanotechnology, pp. 72 91, Springer New York, New York, NY (2007).

[14] S. Raghu, S. Kilarkaje, G. Sanjeev, G.K. Nagaraja and H. Devendrappa: "Effect of electron beam irradiation on polymer electrolytes: Change in morphology, crystallinity, dielectric constant and AC conductivity with dose," Radiation Physics and Chemistry, vol. 98, no. January 2016, pp. 124-131, 2014.

[15] B.S. Chernev, C. Hirschl and G.C. Eder: "Non-destructive determination of ethylene vinyl acetate cross-linking in photovoltaic (PV) modules by raman spectroscopy," Applied Spectroscopy, vol. 67, no. 11, pp. 1296-1301, 2013.

[16] P. Samyn, I. Van Driessche, and G. Schoukens: "Thermal and spectroscopic analysis of worn polyoxymethylene surfaces and wear debris explaining degradation and polymerisation mechanisms," Journal of Polymer Research, vol. 14, no. 5, pp. 411-422, 2007. 